\title{
The role of hand dominance in padel: performance profiles of professional players
}

\author{
Javier Courel-Ibáñez ${ }^{1 *}$, Bernardino Javier Sánchez Alcaraz-Martínez²
}

ORIGINAL ARTICLE

\begin{abstract}
Profiling methods allow coaches to determine players' profiles for designing training programs as specific as possible to maximize performance. We aimed to define the distinctive performance profiles for professional padel players according to technical, spatial, effectiveness and hand dominance characteristics. A multivariate decision tree approach was used to identify and classify players' profiles. Hand dominance comparison revealed a similar technical game pattern along the match $(p=0.330)$ but different effectiveness rates $(p=0.012)$. Left-handed scored more points using smashes $(63.3 \%$ vs. $40.7 \%)$ but made more errors using the wall $(37.7 \%$ vs. $19.5 \%)$; right-handed secured the ball with fewer errors (11.2\% vs. $8.2 \%)$ and more continuity actions (84.9\% vs. $79.9 \%)$. According to these findings, the hand dominance has an important role in players' game style and effectiveness. These differences should be taken into account for designing optimal training programs in padel.

Keywords: training, motion analysis, exercise, racket sports, laterality, teaching.
\end{abstract}

\section{INTRODUCTION}

In sports practice, the assessment of players' behaviours is widely accepted since it allows the identification of strengths and weaknesses to support the training process and preparation for the match (Lames \& McGarry, 2007). A better understanding of effective technical-tactical patterns is essential to help coaches and players making better decisions (Garganta, 2008). In this task, players' performance profiling stands as a helpful tool to determine players' attributes and measure their progress towards set goals (Newman \& Crespo, 2008; O’Donoghue, 2013).

Players' performance in unilateral swinging sports such as tennis, baseball or padel is strongly determined by the competitors' hand dominance (Grouios, Tsorbatzoudis, Alexandris, \& Barkoukis, 2000). Particularly in racket sports such as tennis, evidence reveals certain innate superiority in left-handed athletes (Hagemann, 2009) given a better neuroanatomical condition and visuospatial and visuomotor ability (Holtzen, 2000). Specifically, actions performed with the left hand are under control of the right hemisphere, which is also functionally dominant for visuospatial (Toga \& Thompson, 2003) and spatiotemporal skills (Boulinguez, Ferrois, \& Graumer, 2003). Thus, neural processes may be more efficient (e.g., lower delay or less loss of information) in manual task requiring such skills for left compared to right hand actions (Bisiacchi, Ripoll, Stein, Simonet, \& Azemar, 1985; Dane \& Erzurumluoğlu, 2003). In a more practical term, left-handed hits impose a different spin on balls, which force the opponents (commonly righthanded) to adjust their return stroke reducing the anticipation (Loffing, Hagemann, \& Strauss, $2009,2010)$. This apparent handedness influence has raised the attention of racket sports research and coaches towards detecting performance differences between left- and right handed athletes (Loffing \& Hagemann, 2016). However, there is very limited information available about emerging racket sports such as padel, which particularities (two-on-two, enclosed small-size court) suggest a critical influence of players' handedness in performance.

Padel is a young racket sport, played in doubles on a small size $(10 \times 20 \mathrm{~m})$ and enclosed court (International Padel Federation, 2017).

\footnotetext{
Manuscript received at May 10 ${ }^{\text {th }} 2018$; Accepted at December $10^{\text {th }} 2018$

${ }^{1}$ Faculty of Sport Sciences, University of Murcia, Murcia, Spain

* Corresponding author: javier.courel.ibanez@gmail.com
} 
With only three decades of history, padel has become a mass phenomenon in Spain (counting with over four million regular practitioners) and rapidly spreading in over 27 countries around the world (Courel-Ibáñez, Sánchez-Alcaraz, García Benítez, \& Echegaray, 2017). Research in padel has been mainly focused on describing the match activity and detecting effective performance indicators (Courel-Ibáñez, Sánchez-Alcaraz, \& Cañas, 2015, 2017; Muñoz et al., 2017). These works provided primary information such as the rally duration (3 to $11 \mathrm{~s}$ ), the most common actions in offence (volley and smash) and defence (lob), and highlighted the importance of the net game (involving $80 \%$ of the points). These game dynamics and its effectiveness however could be determined by players' hand dominance (Loffing \& Hagemann, 2016), performance profiles (O'Donoghue, 2013) and game-styles (CourelIbáñez, Sanchez-Alcaraz, \& Muñoz Marín, 2017). Particularly in padel, the optimal use of space and the domain of overhead strokes are essential to enhance performance and increase scoring rate (Courel-Ibáñez, Sanchez-Alcaraz, et al., 2017). In this sense, the players' hand dominance is critical due to the existence of walls surrounding the court that limit players' displacements and actions. For instance, if the pair of players included two right-handed, the one on the right side has the paddle near the sidewall, which sometimes constitutes a limiting factor when returning a ball (Figure 1, Combination 1). This does not happen if including a left-handed on the right side (Figure 1, Combination 2).

This game combination including a lefthanded on the right side allows both players defending the centre line in better conditions (i.e., both using quick and balanced forehand strokes) and makes easy the use of overhead strokes for returning balls near the sidewall (Courel-Ibáñez, Sanchez-Alcaraz, et al., 2017; Muñoz et al., 2017). It is remarkable that the best pair of players in padel history (lasted 13 years on the number one of the ranking winning 170 of 191 finals contested) included this particular game combination (Aguilar-Amat, 2014). Given the apparent advantage of playing with a lefthanded on the right side in padel, a better knowledge on players' performance profiles regarding the players' handedness and the game combination is required to set optimal training plans and goals.
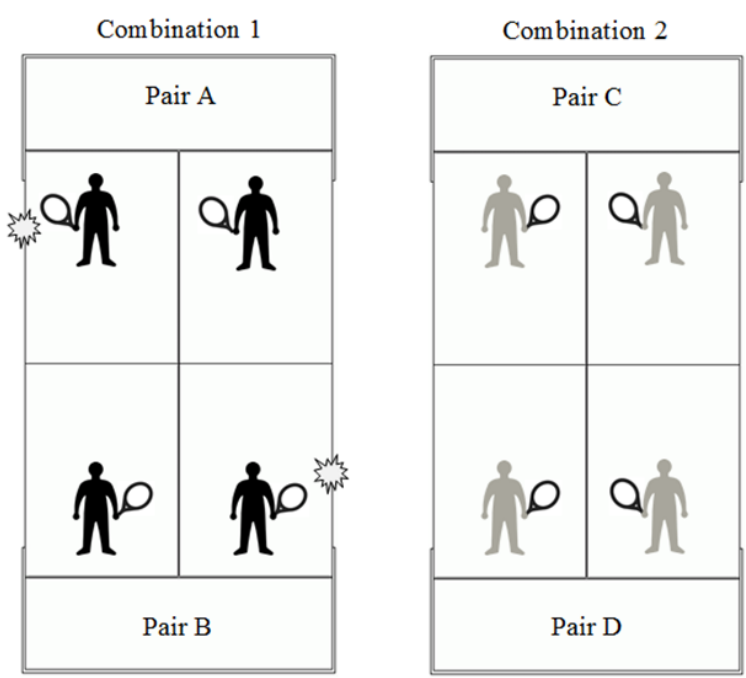

Figure 1. Padel players' combinations regarding hand dominance. Combination 1 includes righthanded on the right side, which limit their movement as the paddle is close to the side walls. Combination 2 solves this problem by including a left-handed player on the right side

Therefore, the aim of this study was to define performance profiles of professional padel players including a left-handed playing on the right side of the court. This information would shed some light on the role of hand dominance in padel and may have implications in designing specific training and conditioning programs according to players' characteristics in real competitive situations.

\section{METHOD}

Evidence suggest that hand dominance is a determinant factor in racket sports. Previous studies in padel have described game dynamics and competition demands regardless players' laterality. This seems to be important in padel given that during a decade, the top-2 padel pairs in the world included a combination of a righthanded playing in the left and a left-handed playing in the right. In this investigation, we assessed professional players' performance by means of technical (groundstroke type), spatial (court depth and court width), and effectiveness (continuity, error and winner) indicators through systematic observation of the competition. 
Besides, a combination of an automated classification method like the decision tree analysis and a visual and practical reporting tool like radar chart were used to define right- and left-handed players' performance profiles.

\section{Participants}

Four professional players (mean (SD) age: 31.7 [4.6] years; height: 181.1 [2.0] cm; weight: 76.4 [3.7] kg) from the 2014 padel championship World Padel Tour (WPT) took part in this study and voluntary provided written informed consent. In these pairs, players from the right side were left-handed and players from the left side were right-handed (Figure 1, combination 2). In total 2,016 groundstroke-by-groundstroke actions were recorded from three official final games of the WPT circuit, played in different weekends with two weeks between each game, according to the official calendar. No injuries were reported. The matches took place during the autumn season in the late afternoon in official indoor padel clubs.

\section{Procedures}

Game dynamics were analyzed regarding the technical (groundstroke type), spatial (court depth and court width), and effectiveness indicators (continuity, error and winner) as described elsewhere (Courel-Ibáñez, SanchezAlcaraz, et al., 2017). Groundstroke types included direct (hit after bouncing in the ground), volley (hit before bouncing in the ground), wall (hit after bouncing in the back or side walls), smash (overhead shot with the racket facing the ground) and bandeja (a sliced smash with the racket facing up). Spatial data were obtained by dividing the court into nine areas and recording the position from where the action was made. Court depth included the net (from the net to the grille zone, $4 \mathrm{~m}$ long), middle (from the 4$\mathrm{m}$ grille zone to the baseline, $3 \mathrm{~m}$ long) and baseline (from the baseline to the back wall, $3 \mathrm{~m}$ long). Court width included the right side (closest area to the right wall, $3 \mathrm{~m}$ width), centre (central lane, $4 \mathrm{~m}$ long width) and left side (closest area to the left wall, $3 \mathrm{~m}$ width). Data were collected by four observers through systematic observation using the specific video software analysis Lince (Gabin, Camerino, Anguera, \& Castañer, 2012). Then, the Kinovea software (V.0.8.15; Kinovea open source project, www.kinovea.org) was used to place a visual grid over the video image to for the court depth data recording. The four observers were coaches specialized in padel (over 5-year experience) and followed a 4-week training program, which include an inter-rater evaluation at the end prior to the observation process. To check inter-rater reliability each observer analyzed a training set of one official padel match, which was not included in the final sample. Consistency of records was analyzed using the free-marginal multirater kappa (Randolph, 2008) and the weighted kappa (Robinson \& O'Donoghue, 2007) obtaining a minimum score of $k=0.82$. Finally, intra-observer evaluation was done at the end of the observation process by Cohen's Kappa calculation, yielding a very good strength of agreement with scores over 0.90 (Altman, 1991). The present study was conducted according to the ethical standards in sport and exercise science research (Harriss \& Atkinson, 2015) and the local Ethics Commission.

\section{Statistical analysis}

Chi-Squared analyses and multivariate decision tree analysis were conducted to identify and classify technical (groundstroke type), spatial (court depth and court width), and effectiveness indicators (continuity, error and winner) regarding players' hand dominance. Significance of associations was identified using the exhaustive CHAID algorithm with following inclusion criteria: (i) nodes with more than 100 iterations, (ii) minimum change in expected cell frequencies of 0.001, and (iii) Pearson chi-square significance level set at $p<0.05$ with Bonferroni's correction (Adj. p). Strength of associations were measured by calculating the Adjusted Standardised Residuals (ASRs) considering values from 1.96 to 2.58 as weak, 2.58 to 3.29 as medium and over 3.29 as strong associations (Field, 2007). Effect size (ES) was estimated by calculating Phi $(\varphi)$ and Cramer's V $(V)$ correlation coefficients, considering $0.10=$ small effect, $0.30=$ medium effect, and $0.50=$ large effect (Fritz, Morris, \& Richler, 2012). 
Statistical analyses were conducted in IBM SPSS v. 20.0 for Windows (Armonk, NY: IBM Corp.).

\section{RESULTS}

The decision tree analysis (Figure 2) showed that $80 \%$ of actions comes from players' own court sides (i.e., right-handed on the left, lefthanded on the right), while the distribution on the centre was more similar. However, the second branch of the tree revealed $20 \%$ more winning actions made by the left-handed on the central lane (Adj. $p<0.046)$.
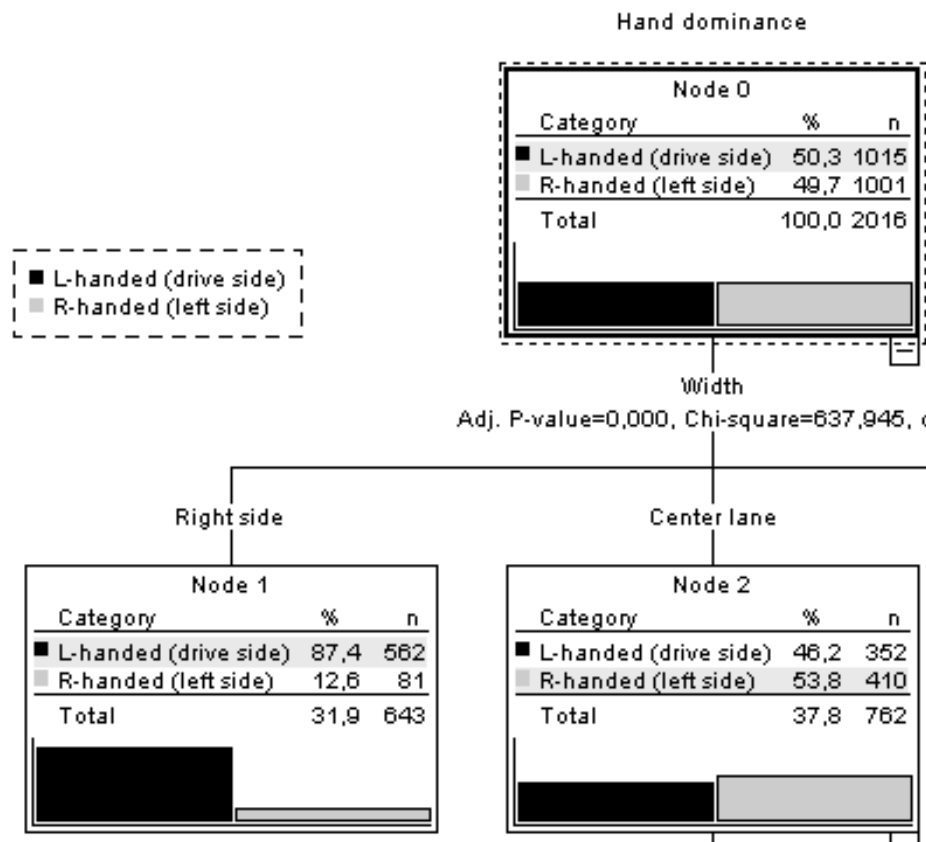

Adj. P-value $=0,000$, Chi-square $=637,945, d f=2$
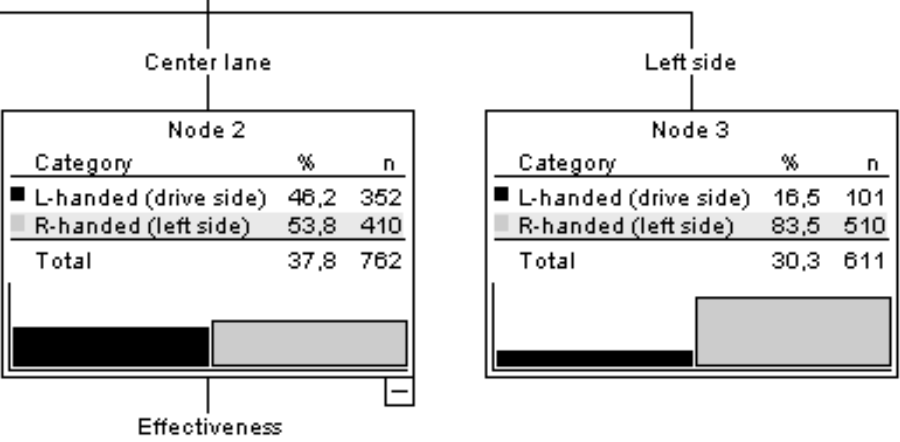

Adj. P-value $=0,046$, Chi-square $=6,379, d f=1$

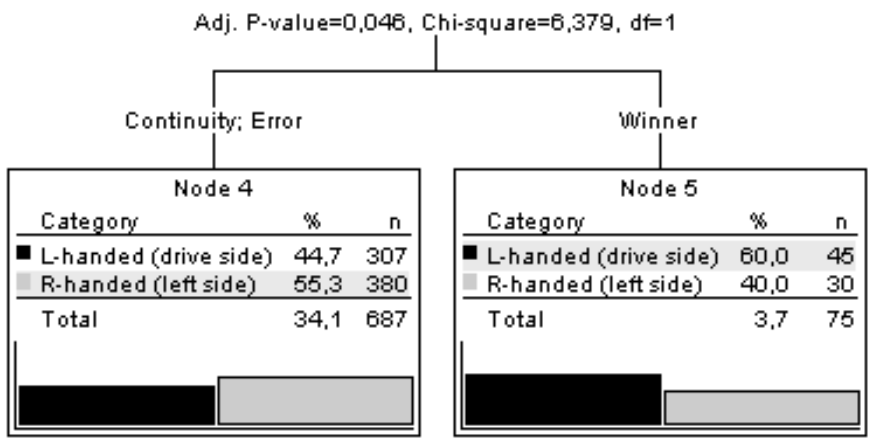

Figure 2. Classification tree model of actions in right- and left-handed padel players according to technical, spatial, and effectiveness indicators.

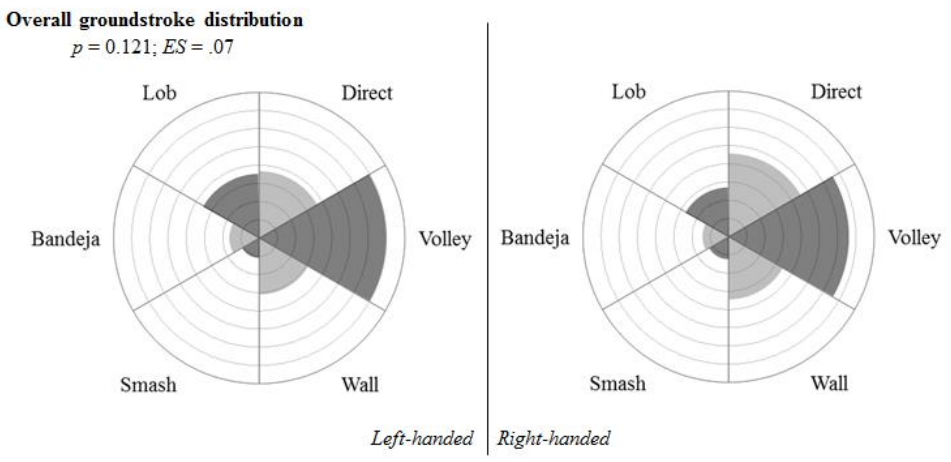

Figure 3. Performance profiles of right- and left-handed padel players regarding groundstroke type. Radial lines represent a $5 \%$ increase 
Figures 3, 4, 5 and 6 depicted the performance profiles of right- and left-handed padel players in radial charts according to technical (groundstroke type), spatial (court depth and court width), and effectiveness indicators (continuity, error and winner). Groundstroke profile (Figure 3) showed a similar use of technical actions between rightand left-handed players $(p=0.121)$.
Court width profiles (Figure 4) revealed a similar pattern on the centre lane $(p=0.791)$. On the sides, right-handed made more lobs on the right side $(25.9 \%$ vs. $13.3 \% ; p=0.049)$. Conversely, left-handed made slightly more volleys on the left (39.6\% vs. $28.8 \%$ ), although differences were not statistically significant $(p=0.274)$.

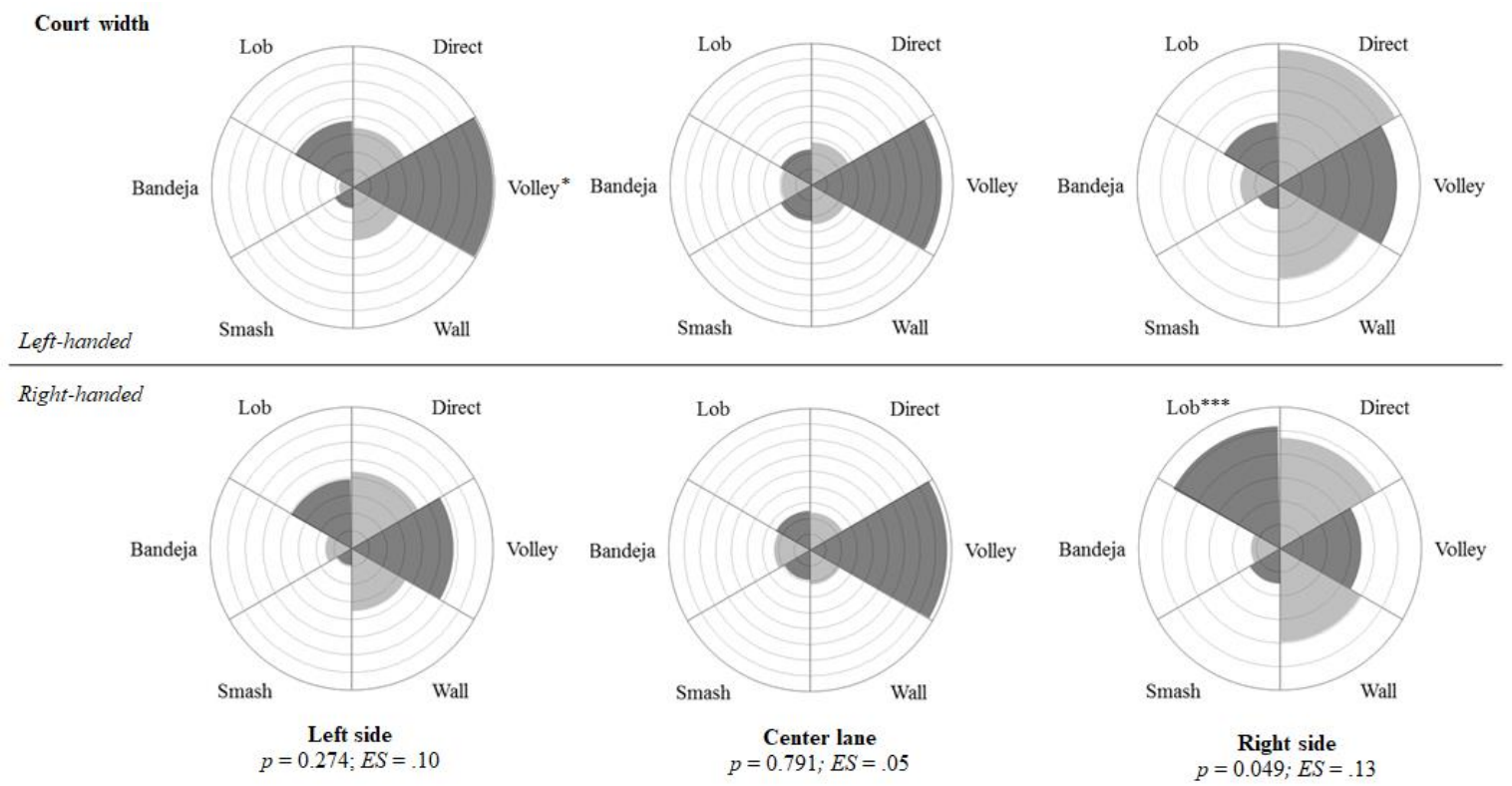

Figure 4. Performance profiles of right- and left-handed padel players regarding court width. Radial lines represent a $5 \%$ increase. Significant positive associations: ${ }^{*}$ weak, ${ }^{* *}$ medium, ${ }^{* * *}$ strong.

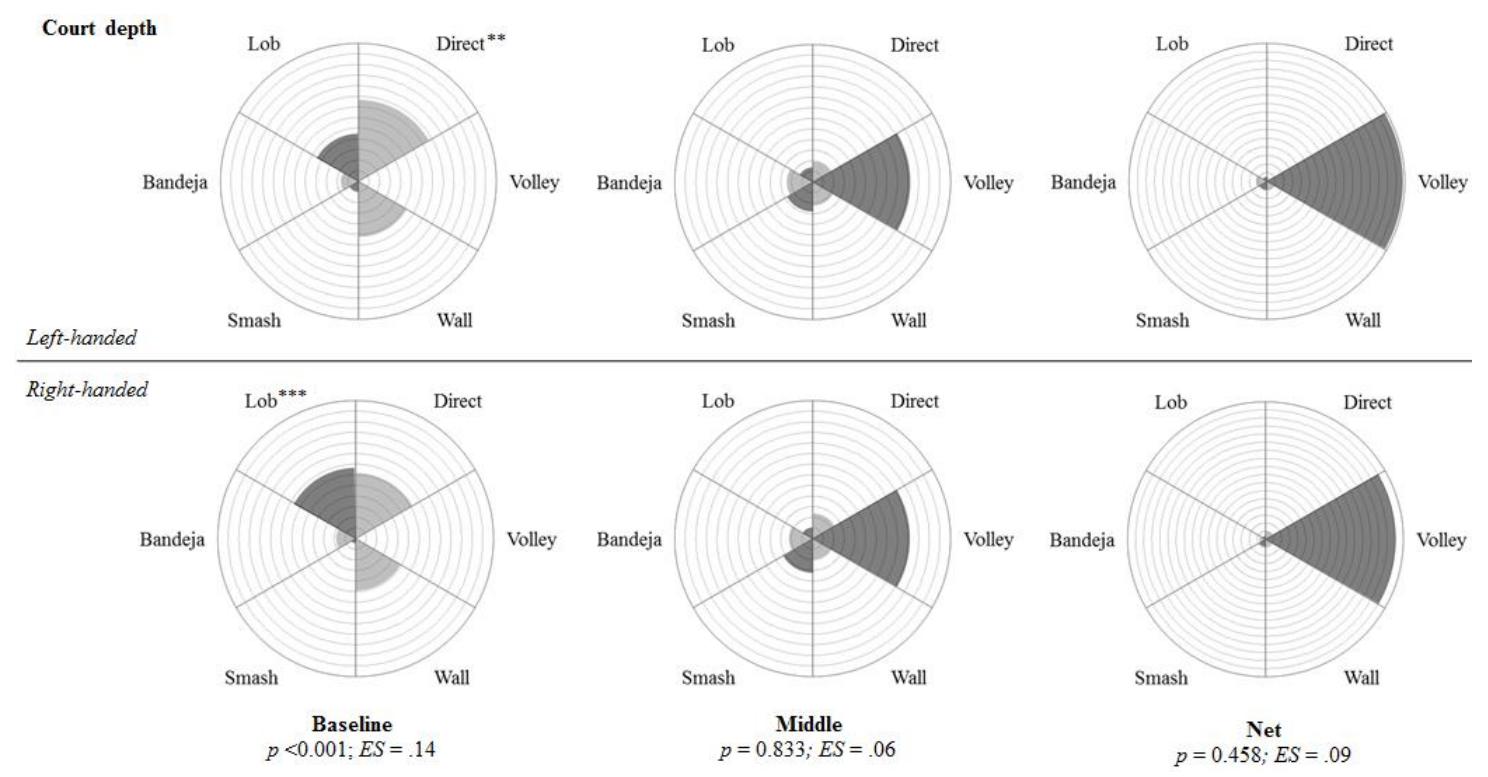

Figure 5. Performance profiles of right- and left-handed padel players regarding court depth. Radial lines represent a $5 \%$ increase. Significant positive associations: ${ }^{*}$ weak, ${ }^{* *}$ medium, ${ }^{* * *}$ strong. 


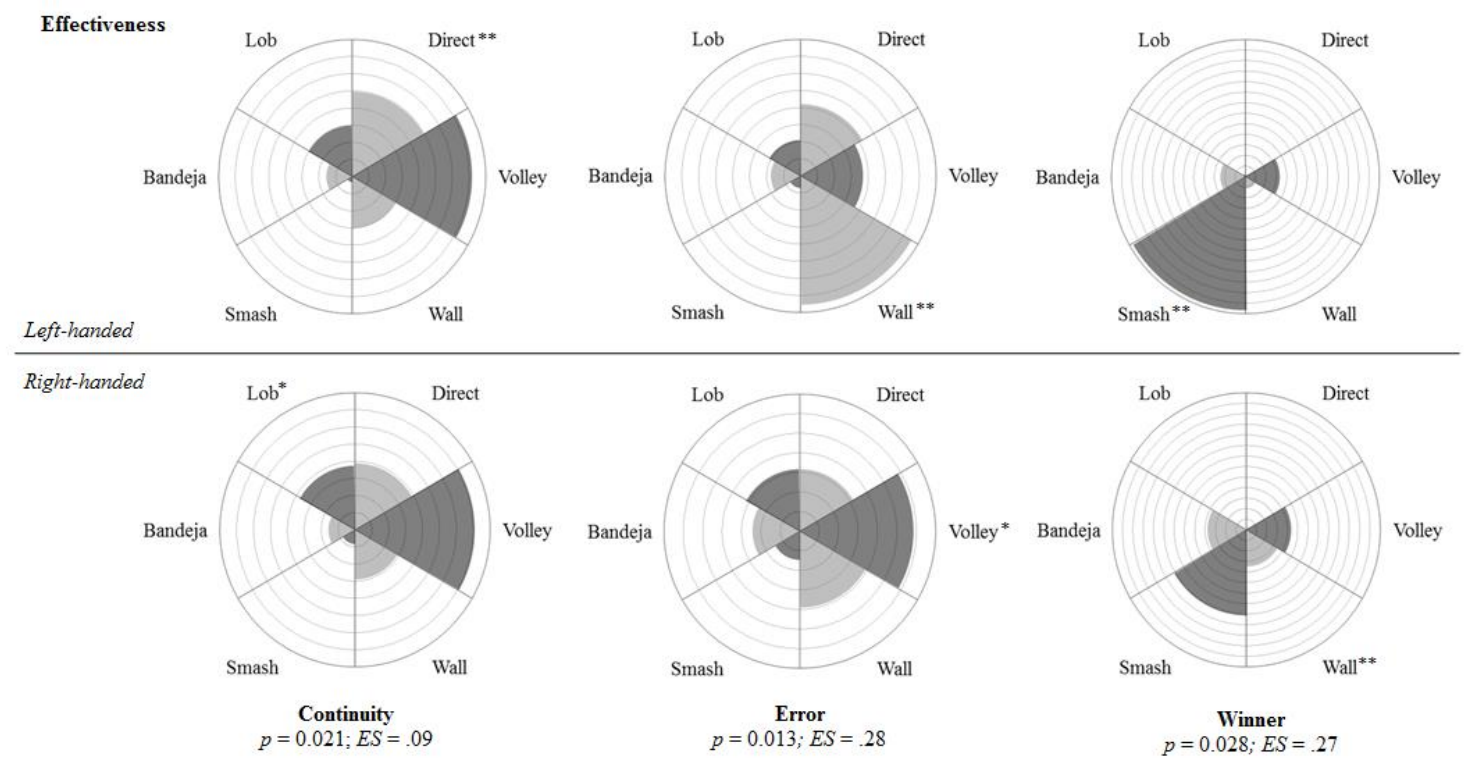

Figure 6. Performance profiles of right- and left-handed padel players regarding effectiveness. Radial lines represent a $5 \%$ increase. Significant positive associations: ${ }^{*}$ weak, ${ }^{* *}$ medium, ${ }^{* * *}$ strong.

Court depth profiles (Figure 5) drew an extremely similar groundstroke distribution on middle $(\mathrm{p}=0.833)$ and net $(\mathrm{p}=0.458)$ areas. Contrariwise, differences were found on the baseline $(\mathrm{p}<0.001$; ES $=.14)$, in where righthanded made more lobs (33.3 \% vs. $22.5 \%$ ) and left-handed made more directs (38.4\% vs. 30.9 $\%)$.

Effectiveness profiles (Figure 6) showed the largest disparities regarding players' hand dominance both in continuity $(\mathrm{p}=0.021$; ES $=$ $.09)$, error $(\mathrm{p}=0.013$; $\mathrm{ES}=.28)$ and winning $(\mathrm{p}$ $=0.028$; ES $=.27)$ actions. Left-handed profile is characterized by using direct to continue the rally $(24.8 \%$ vs. $19.4 \%)$ and smash to score (63.3\% vs. $40.6 \%)$ with larger errors in wall groundstrokes $(37.7 \%$ vs. $19.5 \%)$. In comparison, right-handed used more lob to continue the rally (18.7\% vs. $14.9 \%)$ and wall groundstrokes to score ( $17.4 \%$ vs. $5.6 \%$ ) with larger errors in volleys ( $29.3 \%$ vs. $18.4 \%)$.

\section{DISCUSSION}

This study aimed at defining distinctive performance profiles of professional padel players with respect to their hand dominance. We explored two professional pair of players who used a particular combination including a lefthanded on the right side and a right-handed on the left (Figure 1, combination 2). A similar use of technical actions (i.e., groundstroke type distribution) was found between right- and lefthanded players. This reveals a solid structure of padel game dynamics when using this combination, which can be explained by the fact that both players have the same disposition (i.e., playing with the paddle on their dominant hand and away the side walls). However, effectiveness differed substantially between players: lefthanded were highly more effective using smashes (63.3 \% vs. $40.7 \%$ ) but made more errors when hitting the ball after bouncing on the wall ( $37.7 \%$ vs. $19.5 \%$ ); in turn, right-handed made more lobs (17.2\% vs. $13.2 \%)$ and committed fewer errors (11.2\% vs. $8.2 \%)$. This seems to indicate a specialization of left-handed as 'scorers' and right-handed as 'defenders' when using this combination, which could explain why including a left-handed on the right side has been extremely effective in padel during the last decade. These novel results open the debate about the importance of hand dominance in padel and the risks and benefits of each combination.

Interestingly, our findings showed a very much alike overall game pattern in both rightand left-handed players (Figure 3). This is in line with previous researches (Courel-Ibáñez, Sanchez-Alcaraz, et al., 2017; Lupo et al., 2018; Torres-Luque, Ramirez, Cabello-Manrique, 
Nikolaidis, \& Alvero-Cruz, 2015) suggesting that padel technical actions are quite solidly distributed along a professional padel match. For example, one can expect around $25-35 \%$ of volleys, $20-30 \%$ of directs, $15-25 \%$ of overhead groundstrokes (smashes and bandeja), 15-20\% of walls, and $10-15 \%$ of lobs. However, this distribution seems to be importantly altered regarding the court space, in terms of depth and width (Courel-Ibáñez, Sanchez-Alcaraz, et al., 2017). These authors classified three main game styles according to the court depth: defensive (baseline), transition (middle) and offensive (net). Regarding the width, the centre lane was relevant during the transition and offensive phases, while the sides were more important during the defence. Our findings partly supported this trend during the offence, by identifying a similar groundstroke pattern in right- and left-handed players on net and middle areas (Figure 5). However, from a defensive point of view (i.e., baseline), right-handed made more lobs and left-handed made more directs (Figure 5). The lob is the most common defensive action used in padel, as allow players sending the opponents back while moving to the net to score. Directs are mainly used to speed-up the game and overpass the opponents thorough a low ball crossing the centre lane (Muñoz et al., 2017). In light of this observation, the players' defensive specialization identified in the present study might result beneficial by: a) reducing the risks derived from a short/low lob (i.e., let the opponents returning a smash) and b) using directs to speed-up the game and increase the opponents' errors rate (Courel-Ibáñez \& Sanchez-Alcaraz, 2017; Courel-Ibáñez, SánchezAlcaraz, \& Cañas, 2017). In support of this argument, the exploration of players' opposite sides revealed that right-handed made more lobs on the right side $(25.9 \%$ vs. $13.3 \%)$ and lefthanded made more volleys on the left-side (39.6\% vs. $28.8 \%$ ) (Figure 5); this likely indicates an anticipation of actions because of a predefined strategy against lobs or deep balls, in which the left-handed (scorer) keeps closer the net searching for scoring options while the righthanded (defender) moves back to the baseline, regardless the court side.
A main contribution of the current study is the description of distinctive performance profiles regarding effectiveness and hand dominance in padel (Figure 6). In line with the above-mentioned results, the greater effectiveness reported in left handed smashes (63.3\% vs. $40.7 \%$ ) may indicate an offensive specialization in these players; right-handed, however, were highly effective on the baseline when attacking using the wall (17.4\% vs. $5.6 \%)$. Previous investigations pointed out the importance of overhead strokes to score in padel, mainly from the middle area of the court - up to seven meters from the net (Courel-Ibáñez, Sanchez-Alcaraz, et al., 2017). This is remarkable considering the high frequency of actions during a padel match including around one stroke per second in longduration rallies (Courel-Ibáñez, Sánchez-Alcaraz, \& Cañas, 2017; Torres-Luque et al., 2015). As so, padel players are required to overcome local fatigue on their upper-body dominant side, particularly on shoulders, elbows and wrists during the game, as reported in similar racket sports (Maquirriain, Baglione, \& Cardey, 2016; Ulbricht, Fernandez-Fernandez, MendezVillanueva, \& Ferrauti, 2016). From the variety of padel strokes, the smash implies the highest velocity joint rotation to hit at the maximum speed, which alarmingly increase the probability of suffering an injury in padel (Castillo-Lozano \& Casuso-Holgado, 2017). In light of our findings, future research should address the study of padel players' physical condition to identify the extent to which their performance profile could be related with particular training adaptations (e.g., upper-body power to smash, change of directions to better react after the ball hits the wall).

The generalizability of these findings could be limited because of the reduced size and specificity of the sample. Nevertheless, it is important noted that padel world ranking has been led by pairs of players using a right-left handed combination since the last 15 years. Besides, we are not able to provide data from players' interactions (e.g., if-then rules) and quality of decision making. Future research exploring hand dominance differences in padel is warranted to a better understanding of game 
dynamics and the subsequent designing of training tasks and conditioning programs according to players' characteristics.

\section{CONCLUSION}

Our data suggest distinctive performance profiles in padel players according to their hand dominance. Besides, two player's roles were clearly distinguished: scorer (specialist in direct and volley and smash) and defender (specialist in lob and wall actions). Based on current players' specialization reported, coaches should design specific game plans when competing against right-right or right-left handed pairs in padel. For instance, using lobs against a left-handed opponent appears to be risky if bad performed (increase smash chances) but more effective if succeed (send the offensive player far from scoring areas). Likewise, players should keep an eye on the right-handed when using the wall. In terms of conditioning and skills, it is remarkable the importance of volley (high-frequency, lowvelocity) and smash (low-frequency, highvelocity) actions in padel offence. Physical conditioning and prevention programs in padel are required to reduce injury rates caused by cumulative elbow and wrist vibration in volleys and high velocities of joint rotation in smashed, particularly in left-handed and 'scorer' role players.

\section{Acknowledgments:}

Nothing to declare.

\section{Conflict of interests:}

Nothing to declare.

\section{Funding:}

Nothing to declare.

\section{REFERENCES}

Aguilar-Amat, D. (2014). El último partido de Juan y Bela [The last match of Juan and Bela]. El Mundo. Retrieved from http://www.elmundo.es/deportes/2014/12/22/ 549848d9ca4741e8018b4571.html

Altman, D. G. (1991). Practical statistics for medical research. London: Chapman \& Hall.
Bisiacchi, P. S., Ripoll, H., Stein, J. F., Simonet, P., \& Azemar, G. (1985). Left-Handedness in Fencers: An Attentional Advantage? Perceptual and Motor Skills, $61(2)$, 507-513. https://doi.org/10.2466/pms.1985.61.2.507

Boulinguez, P., Ferrois, M., \& Graumer, G. (2003). Hemispheric asymmetry for trajectory perception. Cognitive Brain Research, 16(2), 219$225 . \quad$ https://doi.org/10.1016/S09266410(02)00276-8

Castillo-Lozano, R., \& Casuso-Holgado, M. J. (2017). Incidence of musculoskeletal sport injuries in a sample of male and female recreational paddletennis players. Journal of Sports Medicine and Physical Fitness, 57(6), 816-721. https://doi.org/10.23736/S00224707.16.06240-X

Courel-Ibáñez, J., \& Sanchez-Alcaraz, B. J. (2017). Efecto de las variables situacionales sobre los puntos en jugadores de pádel de élite. Apunts. Educación Física y Deportes, 121, 72-78. https://doi.org/http://dx.doi.org/10.5672/apun ts.2014-0983.es.\%282017/1\%29.127.07

Courel-Ibáñez, J., Sánchez-Alcaraz, B. J., \& Cañas, J. (2015). Effectiveness at the net as a predictor of final match outcome in professional padel players. International Journal of Performance Analysis in Sport, 15(2), 632-640.

Courel-Ibáñez, J., Sánchez-Alcaraz, B. J., \& Cañas, J. (2017). Game performance and length of rally in professional padel player. Journal of Human Kinetics, 55, 161-169. https://doi.org/10.1515/hukin-2016-0045

Courel-Ibáñez, J., Sánchez-Alcaraz, B. J., García Benítez, S., \& Echegaray, M. (2017). Evolution of padel in Spain according to practitioners' gender and age. Cultura, Ciencia y Deporte, 34(12), 39-46.

Courel-Ibáñez, J., Sanchez-Alcaraz, B. J., \& Muñoz Marín, D. (2017). Exploring game dynamics in padel. Implications for assessment and training. Journal of Strength and Conditioning Research. https://doi.org/http://dx.doi.org/10.1519/JSC.0 000000000002126.

Dane, Ş., \& Erzurumluoğlu, A. (2003). Sex and handedness differences in eye-hand visual reaction times in handball players. International Journal of Neuroscience, 113(7), 923-929. https://doi.org/10.1080/00207450390220367

Field, A. (2007). Discovering Statistics Using SPSS. London: SAGE Publications Ltd.

Fritz, C. O., Morris, P. E., \& Richler, J. J. (2012). Effect size estimates: current use, calculations, and interpretation. Journal of Experimental Psychology: General, 141(1), 2-18.

Gabin, B., Camerino, O., Anguera, M. T., \& Castañer, M. (2012). Lince: Multiplatform sport analysis software. Procedia - Social and Behavioral Sciences, 46 , 4692-4694. https://doi.org/10.1016/j.sbspro.2012.06.320

Garganta, J. (2008). Modelação tática em jogos desportivos: A desejável cumplicidade entre pesquisa, treino e competição. F. Tavares, A. 
Graça, J. Garganta \& I. Mesquita (Eds.), Olhares e Contextos Da Performance Nos Jogos Desportivos, 7((pp. 108-121)), 108-121. https://doi.org/10.1007/s00299-004-0843-6

Grouios, G., Tsorbatzoudis, H., Alexandris, K., \& Barkoukis, V. (2000). Do Left-Handed Competitors Have an Innate Superiority in Sports? Perceptual and Motor Skills, 90(3 suppl), 1273-1282. https://doi.org/10.2466/pms.2000.90.3c.1273

Hagemann, N. (2009). The advantage of being lefthanded in interactive sports. Attention, Perception, \& $\quad$ Psychophysics, 71(7), 1641-1648. https://doi.org/10.3758/APP.71.7.1641

Harriss, D. J., \& Atkinson, G. (2015). Ethical Standards in Sport and Exercise Science Research: 2016 Update. Interational Journal of Sports Medicine, 36(14), 1121-1124. https://doi.org/10.1055/s-0035-1565186

Holtzen, D. W. (2000). Handedness and Professional Tennis. International Journal of Neuroscience, 105(14), 101-119. https://doi.org/10.3109/00207450009003270

International Padel Federation. (2017). Regulations of the padel game. Retrieved May 17, 2017, from https://media.wix.com/ugd/b602c3_f2cea9c6d1 fe4caea85d35f7ea396eb9.pdf

Lames, M., \& McGarry, T. (2007). On the search for reliable performance indicators in game sports. International Journal of Performance Analysis in Sport, $7(1)$,

62-79. https://doi.org/10.1080/24748668.2007.11868 388

Loffing, F., \& Hagemann, N. (2016). Performance Differences Between Left- and Right-Sided Athletes in One-on-One Interactive Sports. In Laterality in Sports: Theories and Applications (pp. 249-277).

Elsevier. https://doi.org/10.1016/B978-0-12-8014264.00012-2

Loffing, F., Hagemann, N., \& Strauss, B. (2009). The Serve in Professional Men's Tennis: Effects of Players' Handedness. International Journal of Performance Analysis in Sport, 9(2), 255-274. https://doi.org/10.1080/24748668.2009.11868 482

Loffing, F., Hagemann, N., \& Strauss, B. (2010). Automated processes in tennis: do left-handed players benefit from the tactical preferences of their opponents? Journal of Sports Sciences, 28(4),
$435-443$.

https://doi.org/10.1080/02640410903536459

Lupo, C., Condello, G., Courel-Ibáñez, J., Gallo, C., Conte, D., \& Tessitore, A. (2018). Effect of gender and match outcome on professional padel competition. RICYDE: Revista Internacional de Ciencias Del Deporte, 14(51), 29-41. https://doi.org/10.5232/ricyde2018.05103

Maquirriain, J., Baglione, R., \& Cardey, M. (2016). Male professional tennis players maintain constant serve speed and accuracy over long matches on grass courts. European Journal of Sport Science, 16(7), 845-849. https://doi.org/10.1080/17461391.2016.11561 63

Muñoz, D., Courel-Ibáñez, J., Sánchez-Alcaraz, B. J., Díaz, J., Grijota, F. J., \& Muñoz, J. (2017). Análisis del uso y eficacia del globo para recuperar la red en función del contexto de juego en pádel [Analysis of the use and effectiveness of lobs to recover the net regarding game context in padel]. Retos, 31, 19-22.

Newman, J., \& Crespo, M. (2008). Performance Profiling in Tennis. ITF Coaching and Sport Science Review, 15(44), 12-16.

O'Donoghue, P. (2013). Sports Performance Profiling. (T. McGarry, P. O’Donoghue, \& J. Sampaio, Eds.), Routledge Handbook of Sports Performance Analysis. London: Routledge.

Randolph, J. J. (2008). Online Kappa Calculator [Computer software]. Retrieved November 29, 2016, from http://justus.randolph.name/kappa

Robinson, G., \& O’Donoghue, P. (2007). A weighted kappa statistic for reliability testing in performance analysis of sport. International Journal of Performance Analysis in Sport, 7(1), 12-19.

Toga, A. W., \& Thompson, P. M. (2003). Mapping brain asymmetry. Nature Reviews Neuroscience, 4(1), 37-48. https://doi.org/10.1038/nrn1009

Torres-Luque, G., Ramirez, A., Cabello-Manrique, D., Nikolaidis, P. T., \& Alvero-Cruz, J. R. (2015). Match analysis of elite players during paddle tennis competition. International Journal of Performance Analysis in Sport, 15(3), 1135-1144.

Ulbricht, A., Fernandez-Fernandez, J., MendezVillanueva, A., \& Ferrauti, A. (2016). Impact of Fitness Characteristics on Tennis Performance in Elite Junior Tennis Players. Journal of Strength and Conditioning Research, 30(4), 989-998. https://doi.org/10.1519/JSC.000000000000126 7 